\title{
Characterization of the Xanthomonas AvrXv4 Effector, a SUMO Protease Translocated into Plant Cells
}

\author{
Julie Roden, Leah Eardley, Andrew Hotson, Yajuan Cao, and Mary Beth Mudgett \\ Department of Biological Sciences, Stanford University, Stanford, CA 94305, U.S.A.
}

Submitted 7 October 2003. Accepted 23 January 2004.

\begin{abstract}
Homologs of the Yersinia virulence factor YopJ are found in both animal and plant bacterial pathogens, as well as in plant symbionts. The conservation of this effector family indicates that several pathogens may use YopJ-like proteins to regulate bacteria-host interactions during infection. YopJ and YopJ-like proteins share structural homology with cysteine proteases and are hypothesized to functionally mimic small ubiquitin-like modifier (SUMO) proteases in eukaryotic cells. Strains of the phytopathogenic bacterium Xanthomonas campestris pv. vesicatoria are known to possess four YopJ-like proteins, AvrXv4, AvrBsT, AvrRxv, and XopJ. In this work, we have characterized AvrXv4 to determine if AvrXv4 functions like a SUMO protease in planta during Xanthomonas-plant interactions. We provide evidence that $X$. campestris pv. vesicatoria secretes and translocates the AvrXv4 protein into plant cells during infection in a type III-dependent manner. Once inside the plant cell, AvrXv4 is localized to the plant cytoplasm. By performing AvrXv4 deletion and mutational analysis, we have identified amino acids required for type III delivery and for host recognition. We show that AvrXv4 recognition by resistant plants requires a functional protease catalytic core, the domain that is conserved in all of the putative YopJ-like cysteine proteases. We also show that AvrXv4 expression in planta leads to a reduction in SUMO-modified proteins, demonstrating that AvrXv4 possesses SUMO isopeptidase activity. Overall, our studies reveal that the YopJ-like effector AvrXv4 encodes a type III SUMO protease effector that is active in the cytoplasmic compartment of plant cells.
\end{abstract}

Additional keywords: bacterial pathogenesis, type III secretion, YopJ family.

Xanthomonas campestris pv. vesicatoria is the causal agent of bacterial spot disease on pepper and tomato plants. $X$. campestris pv. vesicatoria, like several phytopathogenic bacteria, employs the type III secretion system (TTSS) during plant infection to inject bacterial proteins into the plant host cell (Bonas et al. 1991; Fenselau et al. 1992; Hueck 1998). Proteins that traverse the type III pathway are commonly referred to as type III "effector" proteins because they trigger changes in plant physiology that lead to either plant pathogenesis or plant resistance. A number of putative and confirmed type III effectors have been identified in several plant-pathogenic bacteria (Buttner and Bonas 2002; Collmer et al. 2002; da Silva et al. 2002; Greenberg and Vinatzer 2003; White et al. 2000).

Corresponding author: M. B. Mudgett; Telephone: +1.650 .723 .3252 ; Fax: +1.650 .725 .8221 ; E-mail: mudgett@ stanford.edu
However, their precise roles in bacterial colonization, pathogenesis, and the activation of plant defense are still largely unknown.

Most of our knowledge concerning the action of type III effectors in plant cells comes from the study of effectors classified as avirulence (Avr) proteins (White et al. 2000). Avr effector proteins are easily identified because they induce specific defense responses, including localized cell death or the hypersensitive response (HR), in resistant plants. Disease resistance $(\mathrm{R})$ proteins in resistant plants have evolved to recognize the bacterially injected Avr effector protein, either directly or indirectly, inside the plant cell. Such recognition initiates a defense signal transduction cascade during the early stages of infection to prevent the growth and spread of the invading pathogen (Dangl and Jones 2001). In contrast, susceptible plants lack $\mathrm{R}$ proteins (or possess nonfunctional $\mathrm{R}$ proteins) that recognize specific Avr effector proteins. Thus, in these hosts, the invading bacterial pathogen will go unnoticed, multiply, and eventually elicit plant disease symptoms.

The fact that Avr effectors are maintained in most bacterial populations suggests that these proteins play an important role in planta during infection. Avr effectors have been shown to elicit host-specific disease symptoms, to promote pathogen growth, and to suppress host defenses (Abramovitch et al. 2003; Chang et al. 2000; Duan et al. 1999; Hauck et al. 2003; Jackson et al. 1999; Reuber and Ausubel 1996; Ritter and Dangl 1995; Tsiamis et al. 2000). Hence, some type III Avr proteins actually function as virulence factors and contribute to bacterial pathogenesis. The molecular basis for these Avrinduced phenotypes has yet to be determined.

We are interested in elucidating the function of the YopJ family of Avr effectors that are prevalent in X. campestris pv. vesicatoria. YopJ is a type III effector protein that was originally identified in Yersinia pestis, the causal agent of the bubonic plague (Orth 2002). X. campestris pv. vesicatoria strains possess four YopJ-like proteins, AvrXv4, AvrBsT, AvrRxv, and XopJ (Astua-Monge et al. 2000; Ciesiolka et al. 1999; Noel et al. 2001; Whalen et al. 1988). YopJ-like proteins also are found in plant and animal bacterial pathogens, as well as plant symbionts, indicating that this effector class may play an important role in several bacteria-host interactions. Using structural prediction programs, YopJ and YopJ-like effectors were shown to share secondary structure with the CE Clan of cysteine proteases characterized by a cysteine nucleophile and a catalytic core composed of three amino acid residues (histidine, glutamic acid or aspartic acid, and cysteine). Within the CE Clan, YopJ and YopJ-like effectors are assigned to the C55 peptidase family based on additional structural information that distinguishes protease polypeptides. These analyses suggest that these effectors function as cysteine proteases inside host cells. Mutation of the putative catalytic core of YopJ and 
AvrBsT disrupted the action of each protein in their respective host cells, supporting the hypothesis that YopJ and YopJ-like effector proteins encode active cysteine proteases (Orth et al. 2000). Specifically, YopJ requires a functional protease catalytic core to inhibit MAPK and NF- $\mathrm{BB}$ signaling in animal cells, whereas AvrBsT requires a functional protease catalytic core to trigger defense responses in resistant plant cells (Orth et al. 2000).

In addition, it was discovered that the YopJ effector family shares limited structural similarity with the active site of the yeast Ulp1 protease, hinting that YopJ and YopJ-like effectors may mimic Ulp1 activity in eukaryotic cells (Orth et al. 2000). Ulp1 is a cysteine protease that cleaves isopeptide bonds that link the highly conserved small ubiquitin-like modifier (SUMO) to a number of regulatory proteins $(\mathrm{Li}$ and Hochstrasser 1999). Ulp1 functions as a SUMO protease by catalyzing two critical reactions in the SUMO pathway. In the first, Ulp1 functions as a peptidase and processes the invariant C-terminal sequence (-GG XXX) of SUMO to its mature form (-GG) so that the terminal glycine residue can be used as a substrate to modify target proteins covalently (Melchoir 2000). In the second, Ulp1 functions as an isopeptidase. Ulp1 removes (or deconjugates) SUMO from its target protein by cleaving the isopeptide bond that links the C-terminus of SUMO to the $\varepsilon$-amine of a lysine residue on the target protein (Melchoir 2000). Considering the structural homology with the Ulp1 protease, YopJ and YopJ-like effectors were predicted to mimic host SUMO proteases and thereby disrupt host cell signal transduction. Interestingly, the expression of YopJ in animal cells inhibits the conjugation of SUMO to target proteins (Orth et al. 2000). This revealed that the function of YopJ, and possibly YopJ-like effectors, is to disrupt SUMO post-translational modification in infected host cells.

In the course of our work, we found that $X$. campestris pv. vesicatoria possesses a second cysteine protease family sharing structural homology with Ulp1. This family now is referred to as the XopD effector family (Hotson et al. 2003; Noel et al. 2002). In contrast to the YopJ-like effector family, XopD shares striking sequence similarity with the catalytic core of Ulp1. XopD and Ulp1 both are classified as cysteine proteases in the C48 protease family (Hotson et al. 2003). Biochemical studies of XopD in vitro and in planta confirm that

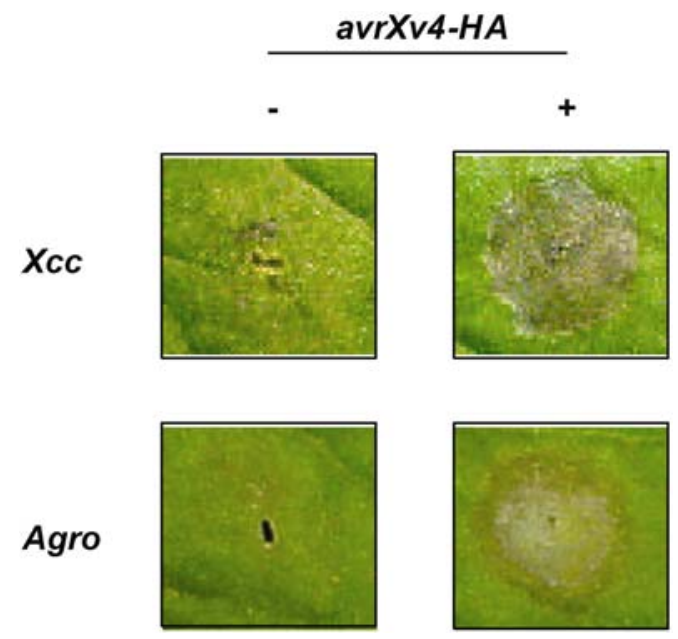

Fig. 1. AvrXv4-dependent hypersensitive response cell death in Nicotiana benthamiana leaves. Xanthomonas campestris pv. campestris (Xcc) strains carrying the empty vector pDD62 or pDD62(avrXv4-HA) were inoculated into leaves at $1 \times 10^{9}$ cells $/ \mathrm{ml}$. Agrobacterium tumefaciens (Agro) strains carrying the empty vector pMDD1 or pMDD1(avrXv4-HA) were inoculated into leaves at $6 \times 10^{8}$ cells $/ \mathrm{ml}$. Symptoms were recorded 24 to $48 \mathrm{~h}$ post inoculation; $-=$ empty vector and $+=a v r X v 4-H A$ gene.
XopD encodes an active cysteine protease with plant-specific SUMO substrate specificity. Moreover, XopD is translocated to subnuclear foci in the plant nucleus during infection, suggesting that XopD-specific SUMO substrates reside within the plant cell nucleus (Hotson et al. 2003). These studies provide direct evidence that XopD mimics endogenous plant SUMO isopeptidases to interfere with SUMO protein conjugation during $X$. campestris pv. vesicatoria infection.

The following question then arises: Why would pathogens like $X$. campestris pv. vesicatoria use proteases to target the SUMO pathway? SUMO is a member of a family of ubiquitin-related proteins that are covalently attached to eukaryotic proteins by a protein conjugation system that operates similarly to the ubiquitin protein conjugation system (Kurepa et al. 2003; Melchoir 2000). In contrast to ubiquitin, SUMO post-translational modification stabilizes proteins and can serve as an antagonist of ubiquitin (Desterro et al. 1998). Importantly, SUMO and SUMO proteases dynamically and reversibly regulate protein function and thus control a number of cellular processes. For example, SUMO modification controls nuclear import, signal transduction, cell-cycle progression, and the stress response (Melchoir 2000). Pathogens that disrupt or interfere with the regulation of protein SUMOylation may have an advantage over their host by affecting a number of host cellular pathways during infection.

Herein, we have addressed the role of a YopJ-like effector in $X$. campestris pv. vesicatoria-plant interactions. We explored the possibility that AvrXv4 encodes an active SUMO protease that is injected into plant cells during infection. We demonstrated that AvrXv4 is secreted and translocated into plant cells by the type III secretory pathway. In planta localization studies revealed that, once inside the plant cell, the AvrXv4 protein is excluded from the plant nucleus and accumulates in the plant cytoplasm. Mutation of AvrXv4's putative protease core residues resulted in a loss of AvrXv4-dependent HR in resistant plant hosts, revealing that the conserved protease domain is essential for the activation of host defenses. Purified AvrXv4 protein did not exhibit any detectable SUMO protease activity in vitro. However, transient expression of the AvrXv4 protein in Nicotiana benthamiana and pepper led to a loss of SUMOylated proteins in planta. Thus, our studies show that the YopJlike effector AvrXv4 encodes a protease with SUMO substrate specificity that is localized to the cytoplasmic compartment of the plant cell.

\section{RESULTS}

\section{N. benthamiana plants recognize AvrXv4 and elicit HR.}

AvrXv4 is an avirulence protein in X. campestris pv. vesicatoria strain 91-118 that induces an XV4-dependent HR in the wild tomato relative Lycopersicon pennellii (Astua-Monge et al. 2000). In contrast, L. esculentum plants are susceptible to this infection and do not develop the HR (Astua-Monge et al. 2000). In the course of our studies, we found that an AvrXv4dependent HR also is elicited in $N$. benthamiana plants when they are infected with Xanthomonas strains expressing untagged AvrXv4 (data not shown) and HA-tagged AvrXv4HA (Fig. 1). X. campestris pv. campestris strain 8004 was used to infect $N$. benthamiana because it does not elicit a HR, whereas $X$. campestris pv. vesicatoria 91-118 elicits a HR triggered by an unknown effector protein (data not shown). The phenotype and timing for the $X$. campestris pv. campestris AvrXv4-dependent HR in N. benthamiana was similar to that observed for the $X$. campestris pv. vesicatoria 91-118 AvrXv4dependent HR in L. pennellii (data not shown). This indicates that the disease resistance pathway required for the specific recognition of AvrXv4 and the subsequent activation of HR 
also is present in $N$. benthamiana. We also found that transient expression of AvrXv4 in N. benthamiana produced a stronger and more reliable HR phenotype than that observed in L. pennellii. Thus, we used $N$. benthamiana plants to examine the phenotype of all AvrXv4 wild-type and mutant proteins constructed in this work.

\section{AvrXv4 expression in planta induces HR.}

First, we determined whether the expression of the AvrXv4 protein inside plant cells is sufficient to elicit the HR. We expressed AvrXv4 in N. benthamiana using the Agrobacteriummediated transient expression assay (Scofield et al. 1996; Tang et al. 1996). Transient expression of AvrXv4 induced a HR in $N$. benthamiana 24 to $48 \mathrm{~h}$ postinoculation (Fig. 1). This demonstrates that the AvrXv4 protein is sufficient for the activation of disease resistance-mediated cell death and that recognition of AvrXv4 occurs inside plant cells. Furthermore, this data suggests that AvrXv4 is an effector protein that is injected into the plant cell by $X$. campestris pv. vesicatoria, presumably by the TTSS.

\section{Type III-dependent secretion and translocation of AvrXv4 from X. campestris pv. vesicatoria.}

To ascertain if $X$. campestris pv. vesicatoria translocates AvrXv4 via the hrp-encoded TTSS into plant cells during infection, we employed the calmodulin-dependent adenylate cyclase domain (Cya) of Bordetella pertussis cyclolysin as a sensitive reporter protein (Sory and Cornelis 1994). We constructed a translational C-terminal fusion of the Cya reporter to the mature AvrXv4 protein (359 amino acids [aa]) (AvrXv4Cya) and to the first 100 aa residues of AvrXv4 (AvrXv4 ${ }_{1-100^{-}}$ Cya). Cya enzymatic activity requires eukaryotic calmodulin for the production of cAMP. Therefore, the Cya reporter protein produced in the bacterium must be translocated into the eukaryotic cell to be activated. If the AvrXv4-Cya fusion protein contains a type III-dependent secretion and translocation signal, then the bacterium will inject the reporter protein into the host cell by the TTSS and cAMP levels in planta will increase concomitantly during the course of the bacterial infection.

To study AvrXv4 secretion and translocation, we used the Cya reporter assay conditions that previously were optimized for the study of $X$. campestris pv. vesicatoria type III-dependent protein trafficking in pepper cells (Casper-Lindley et al. 2002; Hotson et al. 2003). The following X. campestris pv. vesicatoria strains were used for secretion experiments and plant infections: i) strain $85^{*}$, ii) strain $85^{*} \Delta h r c V$, and iii) strain $85^{*} \Delta h r p F . X$. campestris pv. vesicatoria strain $85^{*}$ constitutively expresses the hrp genes encoding the TTSS due to a

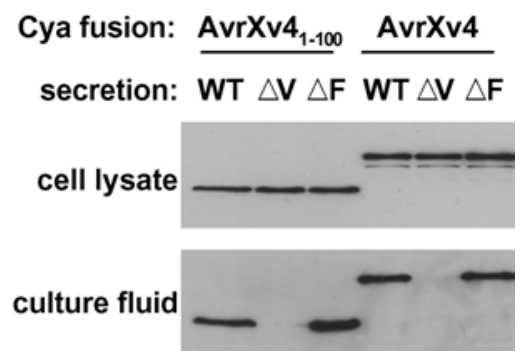

Fig. 2. Type III secretion of AvrXv4 $4_{1-100^{-}}$Cya and AvrXv4-Cya fusion proteins from Xanthomonas campestris pv. vesicatoria. Immunoblot analysis of cellular lysate and culture fluid isolated from $X$. campestris pv. vesicatoria strains $85^{*}$ expressing AvrXv44 ${ }_{1-100}$-Cya and AvrXv4-Cya fusion proteins from the pVSP61 vector. Fusion proteins were detected using the calmodulin-dependent adenylate cyclase domain (Cya) antisera at a $1: 1000$ dilution. $\mathrm{WT}=$ wild type, $\Delta \mathrm{V}=h r c V$ secretion mutant, $\Delta \mathrm{F}=$ $h r p F$ translocation mutant. mutation in the regulatory gene $h r p G$ (Wengelnik et al. 1999). Importantly, $85^{*}$ secretes more protein than wild-type strain, enabling the easy detection of protein in bacterial culture fluids and infected plant tissue. X. campestris pv. vesicatoria strain $85^{*} \Delta h r c V$ is a TTSS secretion-deficient strain (Rossier et al. 1999) and strain $85^{*} \Delta h r p F$ is a TTSS translocation-deficient strain (Buttner et al. 2002; Casper-Lindley et al. 2002). We used pepper as the plant host instead of $N$. benthamiana because pepper does not recognize AvrXv4 (data not shown), and, like tomato, it is a natural host for X. campestris pv. vesicatoria. We were particularly interested in studying AvrXv4 type III secretion and translocation in a susceptible $X$. campestris pv. vesicatoria-plant interaction.

We first checked whether the mature AvrXv4-Cya fusion protein exhibited an AvrXv4-dependent HR in resistant $N$. benthamiana plants. AvrXv4-Cya, expressed by Xanthomonas or Agrobacterium tumefaciens, elicited an HR in N. benthamiana, indicating that the Cya reporter protein was not interfering with AvrXv4 delivery or recognition in planta (data not shown). We next addressed whether $X$. campestris pv. vesicatoria secretes the Cya fusion proteins via the TTSS system. Cell lysate and culture fluid fractions were isolated from $X$. campestris pv. vesicatoria $85^{*}, 85^{*} \Delta h r c V$, and $85^{*} \Delta h r p F$ expressing either AvrXv4 $4_{1-100^{-}}$-Cya or AvrXv4-Cya in pH 5.4 secretion media (Rossier et al. 1999). Immunoblot analysis shows that AvrXv4 ${ }_{1-100}$-Cya and AvrXv4-Cya are present in cellular lysate from $X$. campestris pv. vesicatoria $85^{*}, 85^{*}$ $\Delta h r c V$, and $85^{*} \Delta h r p F$ (Fig. 2). Only the secretion competent strains, $85^{*}$ and $85^{*} \Delta h r p F$, released the respective Cya fusion

A

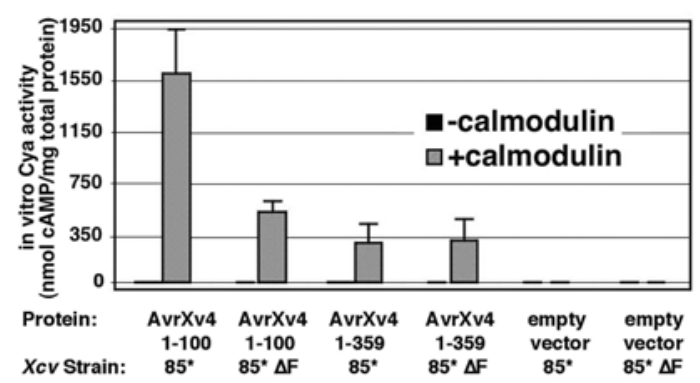

B

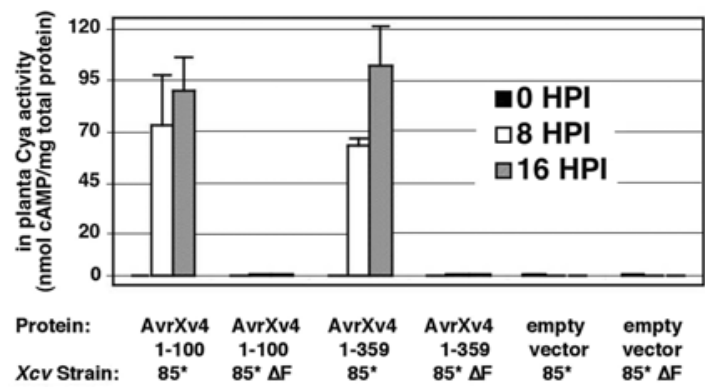

Fig. 3. Calmodulin-dependent adenylate cyclase (Cya) activity of AvrXv4 ${ }_{1-100}-$ Cya and AvrXv4-Cya fusion proteins expressed in vitro and in planta. A, Endogenous in vitro Cya enzymatic activity in bacterial extracts in the absence (black bars) and presence (striped bars) of added calmodulin. The following Xanthomonas campestris pv. vesicatoria strains were analyzed: $85^{*} \mathrm{AvrXv} 4_{1-100}-\mathrm{Cya}, 85^{*} \Delta h r p F$ AvrXv4 $4_{1-100}-\mathrm{Cya}$,

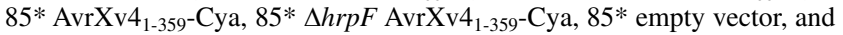
$85^{*} \Delta h r p F$ empty vector. $\mathbf{B}$, In planta Cya enzymatic activity in $X$. campestris pv. vesicatoria-infected pepper leaves at 0 (black bars), 8 (white bars), and 16 (striped bars) h post inoculation (HPI). Leaves were infected with the same $X$. campestris pv. vesicatoria strains described in A. Each value is an average of three independent measurements of cAMP. Data represents the mean Cya activity measured as nmol of cAMP per mg of total protein \pm sample standard deviation. 
protein into the culture fluid (Fig. 2). We confirmed that the proteins present in the culture fluid were not the result of $X$. campestris pv. vesicatoria cell lysis by repeating the immunoblot analysis using antisera for NPTII, a cytoplasmic protein encoded by the plasmid pDD62 in each strain. NPTII protein was detected only in the bacterial cell lysate and not the culture fluid fractions (data not shown). This data reveals that AvrXv4 is secreted by the hrp-encoded TTSS in $X$. campestris pv. vesicatoria and that the first 100 aa of AvrXv4 are sufficient for the in vitro secretion of the Cya reporter protein. Importantly, this data shows that the Cya reporter does not impair AvrXv4 or AvrXv4 $4_{1-100}$ secretion in vitro.

Protein extracts then were isolated from $X$. campestris pv. vesicatoria $85^{*}$ and $85^{*} \Delta h r p F$ expressing AvrXv4 $4_{1-100}-\mathrm{Cya}$ and AvrXv4-Cya protein in liquid culture to test for endogenous Cya enzyme activity. Neither Cya fusion protein possessed endogenous Cya enzyme activity, as expected (Fig. 3A). However, Cya enzyme activity could be reconstituted when calmodulin was added to the bacterial protein extract (Fig. 3A), demonstrating that each chimeric Cya fusion protein encodes a functional cyclase. To study AvrXv4-specific translocation in planta, the same strains were inoculated into pepper leaves. Leaf tissue was collected at 8 and $16 \mathrm{~h}$ postinoculation. Tissue then was analyzed for Cya activity by measuring the production of cAMP. Pepper leaves infected with $X$. campestris pv. vesicatoria $85^{*}$ expressing either the AvrXv4 $4_{1-100}-$ Cya or the AvrXv4-Cya fusion protein accumulated cAMP in a $h r p F$ - and time-dependent manner (Fig. 3B). This data shows that $X$. campestris pv. vesicatoria secretes AvrXv4 via the Hrp TTSS and translocates it directly through the cell wall into the interior of the plant cell. Furthermore, the $\mathrm{N}$-terminal 100 aa of AvrXv4 are sufficient to target the type III-dependent secretion and translocation of the Cya reporter to plant cells.

\section{Identification of AvrXv4's in planta effector domain by deletion analysis.}

We next performed mutagenesis of AvrXv4 to determine the peptide domain that is required for AvrXv4-dependent HR in $N$. benthamiana plants. AvrXv4 N-terminal deletions were constructed by introducing the avrXv4 promoter and start ATG before AvrXv4-HA codon 20, 40, 60, 80, and 94, creating AvrXv4 ${ }_{20-359}$-HA, AvrXv4 $4_{40-359}$-HA, AvrXv4 ${ }_{60-359}-\mathrm{HA}$, AvrXv4 ${ }_{80-359}-\mathrm{HA}$, and AvrXv4 $4_{94-359}-\mathrm{HA}$, respectively (Table 1). $X$. campestris pv. campestris expressed all of the expected $\mathrm{N}$ terminal deleted AvrXv4 polypeptides, except for AvrXv4 40 359-HA (Table 1). When the same strains were hand inoculated into $N$. benthamiana leaves, only $X$. campestris pv. campestris, expressing the full-length AvrXv4-HA polypeptide, induced an AvrXv4-dependent HR (Table 1). None of the N-terminally deleted polypeptides elicited an HR in $N$. benthamiana because the polypeptides lacked the N-terminal amino acids that compose the type III signal sequence (Figs. 2 and 3B). Therefore, $X$. campestris pv. campestris expressed the truncated forms of AvrXv4 but could not inject them into N. benthamiana.

To directly test if the N-terminal amino acids of AvrXv4 are required for AvrXv4 recognition in planta, AvrXv4 $20-359-\mathrm{HA}$, AvrXv4 $40-359-\mathrm{HA}, \quad \mathrm{AvrXv}_{60-359}-\mathrm{HA}, \quad \mathrm{AvrXv}_{80-359}-\mathrm{HA}$, and AvrXv4 ${ }_{94-359}$-HA were transiently expressed in planta using the Agrobacterium-mediated expression assay. An AvrXv4dependent HR was induced only by wild-type AvrXv4-HA and AvrXv4 ${ }_{20-359}$-HA (Table 1). Considering that AvrXv440-359-HA was not expressed, it remains to be determined if amino acids 20 to 39 are required for AvrXv4 recognition in planta. Overall, these data show that the first 19 aa are dispensable for AvrXv4 recognition in planta, yet are critical for delivery into the host cell.

\section{AvrXv4 putative protease domain is required \\ for $\mathrm{HR}$ induction.}

We next investigated the possibility that AvrXv4 may also function as a cysteine protease in planta during $X$. campestris pv. vesicatoria pathogenesis. The putative catalytic triad of AvrXv4 consists of histidine 155, glutamic acid 175, and cysteine 219 . We independently mutagenized each of these residues to alanine (H155A, E175A, or C219A, respectively) and then examined each protein for AvrXv4-dependent HR induction in $N$. benthamiana. Alanine mutations were introduced into untagged AvrXv4 and tagged AvrXv4-HA proteins. Similar phenotypes were observed for untagged (data not shown) and tagged mutant AvrXv4 proteins (Fig. 4A; Table 1). Importantly, the HA epitope did not alter the AvrXv4 HR phenotype in leaves (Fig. 4A). Mutation of the conserved histidine (H155A) or cysteine (C219A) in AvrXv4 completely abolished the ability of $X$. campestris pv. campestris to elicit an HR in $N$. benthamiana (Fig. 4A; Table 1). However, mutation of the conserved glutamic acid (E175A) in AvrXv4 only partially reduced AvrXv4 HR induction in planta. We verified that each AvrXv4 mutant protein was stably expressed (Fig. 4B) and secreted (Fig. 4C) from $X$. campestris pv. vesicatoria in a type III-dependent manner. We also confirmed that the proteins present in the culture fluid were not the result of $X$. campestris pv. vesicatoria cell lysis by repeating the immunoblot analysis using antisera for NPTII, a cytoplasmic protein encoded by the

Table 1. Phenotypes of AvrXv4 polypeptides expressed by Xanthomonas campestris pv. vesicatoria and by Agrobacterium-mediated transformation in Nicotiana benthamiana leaves ${ }^{\mathrm{a}}$

\begin{tabular}{|c|c|c|c|c|c|}
\hline \multirow[b]{2}{*}{ AvrXv4 protein } & \multicolumn{2}{|c|}{ X. campestris pv. campestris expression } & \multicolumn{2}{|c|}{ A. tumefaciens expression in planta } & \multirow{2}{*}{$\frac{X . \text { campestris pv. vesicatoria } 85^{*}}{\text { Secretion }}$} \\
\hline & Phenotype & Protein & Phenotype & Protein & \\
\hline \multicolumn{6}{|l|}{ Mature protein } \\
\hline $1-359$ & HR & Yes & HR & Yes & Yes \\
\hline 1-359-HA & HR & Yes & HR & Yes & Yes \\
\hline \multicolumn{6}{|l|}{$\mathrm{N}$-terminal deletions } \\
\hline 20-359-HA & NS & Yes & HR & Yes & NT \\
\hline 40-359-HA & NS & No & NS & No & NT \\
\hline 60-359-HA & NS & Yes & NS & Yes & NT \\
\hline 80-359-HA & NS & Yes & NS & Yes & NT \\
\hline 94-359-HA & NS & Yes & NS & Yes & NT \\
\hline \multicolumn{6}{|l|}{ Catalytic core mutants } \\
\hline 1-359-HA (H155A) & NS & Yes & NS & Yes & Yes \\
\hline 1-359-HA (E175A) & w-HR & Yes & w-HR & Yes & Yes \\
\hline 1-359-HA (C219A) & NS & Yes & NS & Yes & Yes \\
\hline
\end{tabular}

${ }^{\mathrm{a}} \mathrm{HR}=$ hypersensitive response, $\mathrm{w}-\mathrm{HR}=$ weak $\mathrm{HR}$ activity, NS = no symptoms, and NT = not tested.

${ }^{\mathrm{b}}$ Codon numbering is based on the first methionine for the predicted protein (Astua-Monge et al. 2000). 
plasmid pDD62 in each strain. NPTII protein was detected only in the bacterial cell lysate and not the culture fluid fractions (data not shown). Similar phenotypes were observed for each AvrXv4 catalytic core mutant when the respective mutant protein was transiently expressed in $N$. benthamiana using the Agrobacterium-mediated expression assay (Table 1). Thus, the mutant phenotypes observed in planta are due to a loss of AvrXv4 function or recognition and not due to impairment in the secretion of the protein from the bacterium. These data show that AvrXv4 requires a functional protease catalytic core to elicit AvrXv4-dependent responses in planta.

\section{AvrXv4 SUMO isopeptidase activity.}

Our mutational analysis of the AvrXv4 putative catalytic domain supports the hypothesis that AvrXv4 may function as a cysteine protease in plant cells (Fig. 4; Table 1). To determine if AvrXv4 encodes an active cysteine protease with SUMO substrate specificity, we first purified AvrXv4 as a GST-fusion protein from Escherichia coli and incubated it with a tomato SUMO substrate (data not shown). GST-AvrXv4 was unable to cleave the tomato SUMO substrate, indicating that the purified protein did not have SUMO protease activity in vitro (data not shown). Next, we assessed whether or not plant proteins conjugated with tomato SUMO were substrates for AvrXv4 in planta. Wild-type AvrXv4-HA and mutant AvrXv4-HA C219A were coexpressed with tomato HA-SUMO in $N$. benthamiana and pepper leaves using the Agrobacterium-mediated transient expression assay. As a control, we included the characterized $X$. campestris pv. vesicatoria SUMO protease XopD-HA in our analysis (Hotson et al. 2003). Infected N. benthamiana and pepper tissue was collected 24 and $48 \mathrm{~h}$ postinoculation, respectively. Total protein was extracted from the infected leaves and then AvrXv4-HA, XopD-HA, HA-SUMO, and HA-SUMO protein conjugates were analyzed by immunoblot analysis.

Transient expression of HA-SUMO, AvrXv4-HA, AvrXv4HA C219A, XopD-HA, and XopD-HA C470A in N. benthamiana led to the accumulation of the respective proteins (Fig. 5A, lanes 1 to 5) as well as high molecular weight SUMO protein conjugates (lane 1). Coexpression of wild-type AvrXv4$\mathrm{HA}$ and HA-SUMO in $N$. benthamiana caused a reduction in the level of HA-SUMO-protein conjugates (Fig. 5A, lane 6). Coexpression of the mutant AvrXv4-HA C219A and HASUMO did not alter HA-SUMO-protein conjugates (Fig. 5A, lane 7). Similar results were observed with the control XopD SUMO protease (Hotson et al. 2003) (Fig. 5A, lanes 8 and 9). It is important to note that samples were obtained prior to the induction of the HR triggered by AvrXv4 in N. benthamiana. Typically, HR symptoms are observed 28 to $48 \mathrm{~h}$ postinoculation. To confirm that the loss of SUMO substrates in $N$. benthamiana was due to AvrXv4 proteolysis and not to the activation of HR defenses, we performed analogous experiments with AvrXv4 in pepper. The AvrXv4 effector does not elicit an HR in pepper (data not shown). Again, we observed that only the wild-type AvrXv4-HA protein prevented the accumulation of SUMO-modified proteins in pepper (Fig. 5B, lanes 4 and 5). Collectively, these studies demonstrate that AvrXv4 possesses SUMO isopeptidase enzymatic activity in planta. Moreover, the fact that we were able to detect AvrXv4 protease activity only in vivo suggests that the enzyme may be activated within the host plant.

\section{Localization of AvrXv4 protein in planta.}

To further characterize the role of the putative AvrXv4 protease in planta, we examined its intracellular location in $N$. benthamiana. Related cysteine proteases in the $\mathrm{C} 48$ peptidase family are known to localize to distinct, subcellular sites, imposing a constraint on their enzymatic activity. For example, the $X$. campestris pv. vesicatoria XopD protease is localized to subnuclear foci within the plant nucleus (Hotson et al. 2003) and the yeast Ulp1 protease is localized to the yeast nuclear pore complex (Li and Hochstrasser 2003). The subcellular localization of $X$. campestris pv. vesicatoria cysteine proteases in the C55 peptidase family, including AvrXv4, has not yet been explored. However, a YopJ-like protein in Ralstonia solanacearum, PopP2, is localized to the plant nucleus following transient expression in Arabidopsis thaliana protoplasts (Deslandes et al. 2003).

PSORT analysis of AvrXv4's amino acid sequence indicates that this protein contains three potential nuclear targeting motifs at amino acid position 52 (RPRR), 53 (PRRK), and 256 (RHRK). This analysis suggests that AvrXv4 may also be targeted to the plant nucleus during $X$. campestris pv. vesicatoria infection. To localize AvrXv4 in plant cells, we constructed an enhanced yellow fluorescent protein (EYFP)-tagged AvrXv4 fusion protein, EYFP-AvrXv4, and expressed it in $N$. benthamiana using the constitutive CaMV $35 \mathrm{~S}$ promoter and the Agrobacterium-mediated transient expression assay. Protein expression in the infected plant leaves was confirmed by immunoblot analysis with green fluorescent protein (GFP) antisera (data not shown). The same tissue was analyzed directly using epifluorescence light microscopy.

EYFP-AvrXv4 protein was localized predominately to the cytoplasm of $N$. benthamiana cells (Fig. 6A). In contrast, the EYFP control protein was distributed equally between the cytoplasm and the nucleus (Fig. 6B), whereas the EYFP-XopD control protein was localized specifically to distinct foci within the plant nucleus (Fig. 6C). The EYFP-AvrXv4 fusion encodes a $68-\mathrm{kDa}$ polypeptide. Although this fusion protein potentially could move into the nucleus by passive protein diffusion, nuclear localization of EYFP-AvrXv4 never was observed. This suggests that AvrXv4 is not localized to the plant nucleus and that its site of action is likely the plant cytoplasm.

\section{Growth}

\section{of X. campestris pv. vesicatoria AvrXv4 mutant strain.}

We next determined whether the AvrXv4 effector contributes to the growth of $X$. campestris pv. vesicatoria in susceptible L. esculentum plants. Tomato VF36 leaves were inoculated with wild-type $X$. campestris pv. vesicatoria 91-118 (avrXv4+) and mutant $X$. campestris pv. vesicatoria 91-118 (avrXv4-) suspensions at $1 \times 10^{5}$ cells $/ \mathrm{ml}$ and then sampled for bacteria up to 12 days postinoculation. Consistently, we observed that the mutant $X$. campestris pv. vesicatoria avrXv4- strain exhibited slightly reduced growth compared with the wild-type $X$. campestris pv. vesicatoria avrXv4+ strain (Fig. 7). Similar results were observed in three independent plant growth studies. This analysis indicates that the AvrXv4 protein plays a minor role in $X$. campestris pv. vesicatoria virulence during plant pathogenesis. $X$. campestris pv. vesicatoria $91-118$ contains at least one other YopJ-like effector, AvrBsT. Thus, AvrBsT may compensate for the loss of AvrXv4 function in the mutant $X$. campestris pv. vesicatoria avrXv4- strain. Analysis of $X$. campestris pv. vesicatoria strains mutant for all existing YopJlike proteins will be necessary to carefully determine if this class of type III effectors plays a significant role in $X$. campestris pv. vesicatoria pathogenesis.

\section{DISCUSSION}

We have described the molecular characterization of the $X$. campestris pv. vesicatoria AvrXv4 effector protein. We show that AvrXv4 is a bona fide type III effector protein that is secreted and translocated to the plant cell following $X$. campestris pv. vesicatoria infection. Importantly, we have shown that 
AvrXv4 mimics plant isopeptidases and reduces SUMO-protein conjugates in planta. Moreover, we have shown that AvrXv4, like AvrBsT (Orth et al. 2000), requires the functional protease catalytic core to elicit a defense response in resistant $N$. benthamiana plants. This suggests that the resistance machinery either recognizes a structural component of the AvrXv4 protein or the product or products generated by AvrXv4 proteolysis within infected plant cells. AvrXv4 catalytic core mutants are unable to trigger an HR; therefore, we favor the hypothesis that inappropriate cleavage of several SUMOylated plant substrates by AvrXv4 may be the signal in the plant cell that triggers the activation of an AvrXv4-depend- ent plant disease resistance response. Currently, we do not know the identity of the plant substrates that are attacked by this bacterial protease. Thus, we do not know if the pathogen is disrupting general plant signal transduction or directly interfering with defense signal transduction, possibly regulated by SUMO. The future isolation of AvrXv4 plant substrates should reconcile this issue.

By examining the subcellular localization of AvrXv4 in plant cells, we found that the AvrXv4 protease appears to be restricted to the plant cytoplasm. Conversely, the X. campestris pv. vesicatoria XopD protease is preferentially targeted to plant subnuclear foci (Hotson et al. 2003). Thus, X. campestris
A

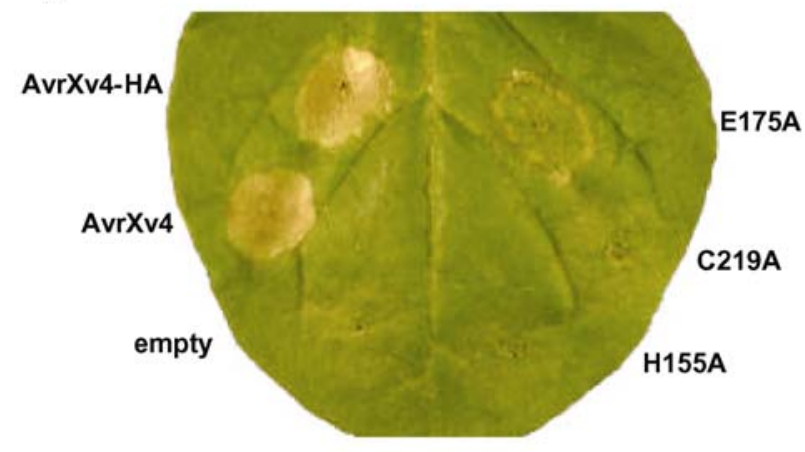

B

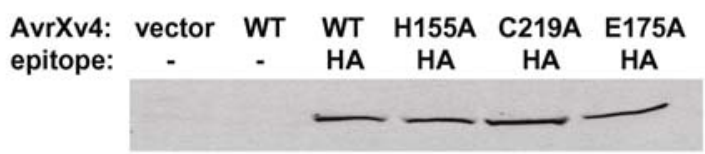

C

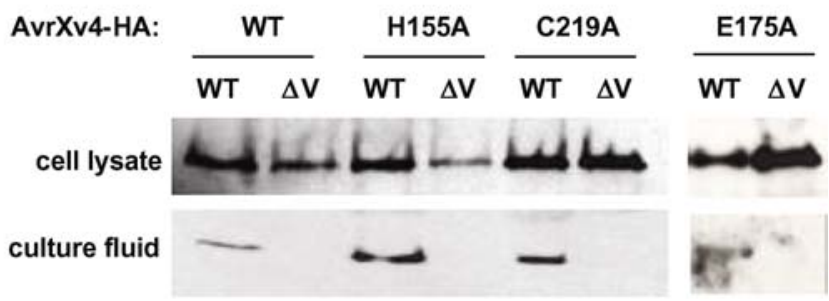

Fig. 4. Mutation of the predicted catalytic core residues in AvrXv4 inhibits AvrXv4-dependent hypersensitive response induction in Nicotiana benthamiana. A, Phenotype of AvrXv4 catalytic core mutants in leaves. Xanthomonas campestris pv. campestris strains expressing empty vector, AvrXv4, AvrXv4-HA, AvrXv4-HA H155A (H155A), AvrXv4-HA C219A (C219A), and AvrXv4-HA E175A (E175A) from the vector pDD62 were inoculated into leaves at $1 \times$ $10^{9}$ cells $/ \mathrm{ml}$. Symptoms were recorded $48 \mathrm{~h}$ post inoculation. B, Expression of AvrXv4 wild-type and mutant proteins in X. campestris pv. campestris. Immunoblot analysis of total protein extracts isolated from X. campestris pv. campestris strains described in A. HA antisera was used at a 1:1000 dilution. C, Type III secretion of AvrXv4 wild-type and mutant proteins from X. campestris pv. vesicatoria $85^{*}$. Immunoblot analysis of cellular lysate and culture fluid isolated from $X$. campestris pv. vesicatoria $85^{*}$ strains expressing proteins described in A. WT $=$ wild type, $\Delta \mathrm{V}=h r c V$ secretion mutant, $\Delta \mathrm{F}=h r p F$ translocation mutant. HA antisera was used at a 1:1000 dilution.

A
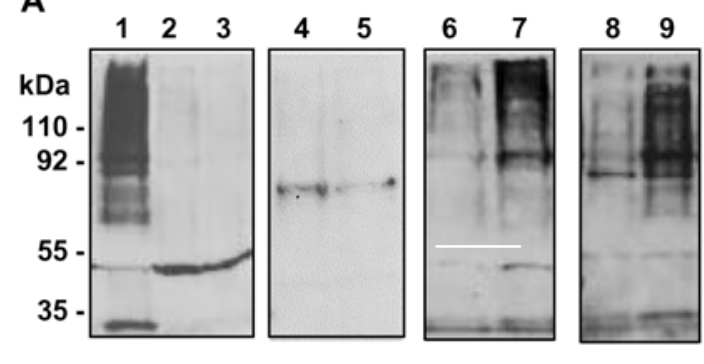

HA-SUMO

protein

conjugates

in $N$. benthamiana

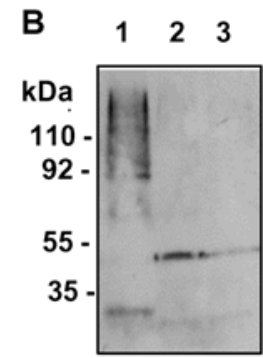

45

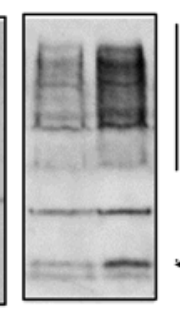

HA-SUMO

protein

conjugates

in pepper

HA-SUMO

Fig. 5. AvrXv4 and XopD-dependent SUMO isopeptidase activity in planta. Leaves were inoculated with single Agrobacterium tumefaciens strains at $6 \times$ $10^{8}$ cells $/ \mathrm{ml}$. For co-inoculations, strains were mixed equally and injected into the leaf at a final density of $1.2 \times 10^{9}$ cells $/ \mathrm{ml}$. Total protein was extracted from Nicotiana benthamiana leaves and pepper leaves at 24 and $48 \mathrm{~h}$ post inoculation, respectively, and was analyzed by immunoblot analysis using HA antisera at a 1:1000 dilution. A, $N$. benthamiana leaves expressing HA-SUMO (lane 1), AvrXv4-HA (lane 2), AvrXv4-HA C219A (lane 3), XopD-HA (lane 4), or XopD-HA C470A (lane 5). HA-SUMO was co-inoculated with AvrXv4-HA (lane 6), AvrXv4-HA C219A (lane 7), XopD-HA (lane 8), or XopD-HA C470A (lane 9). B, Pepper leaves expressing HA-SUMO (lane 1), AvrXv4-HA (lane 2), and AvrXv4-HA C219A (lane 3). HA-SUMO was co-inoculated with AvrXv4-HA (lane 4) or AvrXv4-HA C219A (lane 5). 
pv. vesicatoria appears to send pathogen-derived SUMO proteases to at least two compartments in the plant cell. This implies that the subcellular localization of X. campestris $\mathrm{pv}$. vesicatoria proteases may regulate SUMO protease substrate specificity. Such constraints on SUMO isopeptidase specificity have been reported for the yeast Ulp1 SUMO protease (Li and Hochstrasser 2003). Ulp1 contains an N-terminal regulatory domain that targets the enzyme to the nuclear envelope and restricts Ulp1 activity toward particular SUMO substrates. Removal of the N-terminal regulatory domain enables Ulp1 to cleave a subset of the divergent Ulp2 isopeptidase's substrates and to suppress defects of cells lacking Ulp2 activity. Further characterization of SUMO proteases in the YopJ-like and XopD families should reveal how the protease compartmentalization within plant cells influences enzyme substrate specificity and how each enzyme distinctly affects plant physiology during Xanthomonas pathogenesis.

In contrast to what is known in yeast and animal cells (Melchoir 2000), little is known about the SUMO conjugation pathway or the identity of its target proteins in plant cells. However, a recent report confirms that the SUMO modification system is present in a number of plants (Kurepa et al. 2003). The initial characterization of the SUMO pathway in Arabidopsis thaliana shows that the SUMO conjugation system is more complex than any other system characterized to date. A. thaliana is predicted to use at least 9 SUMOs and 12 SUMO proteases, revealing that SUMOylation and deSUMOylation of proteins are pivotal regulatory steps in protein signal transduction in plants (Kurepa et al. 2003). A diverse array of

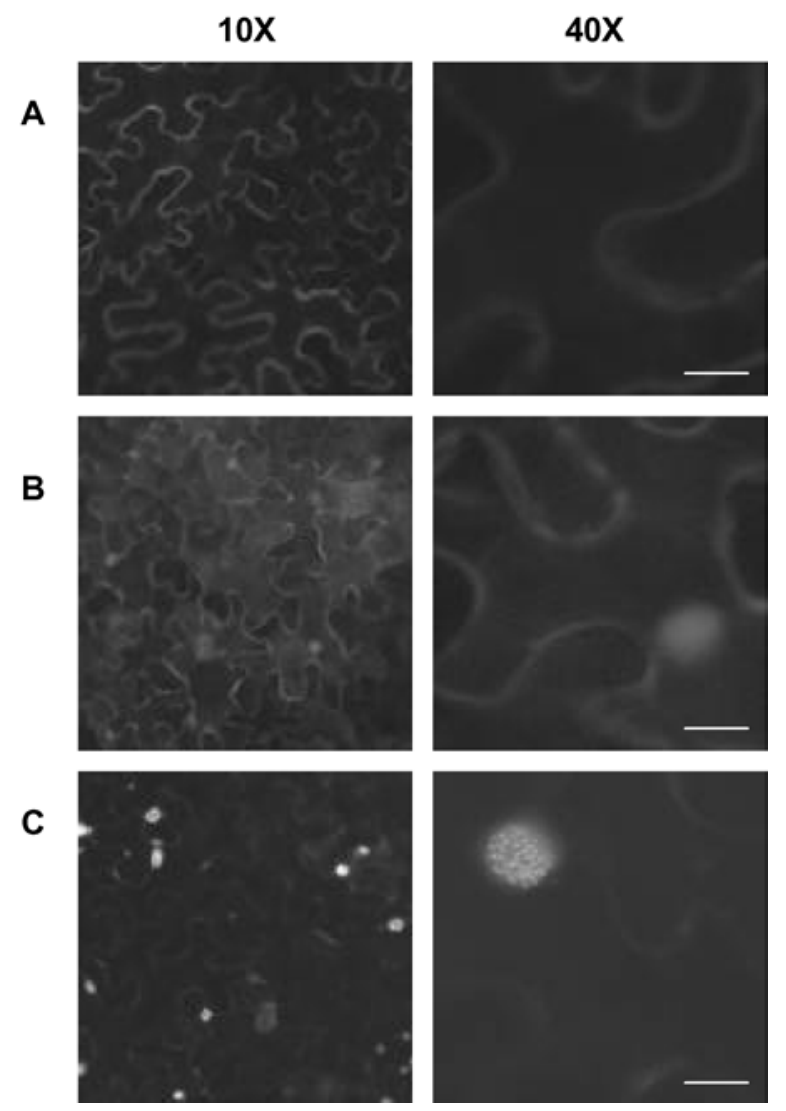

Fig. 6. Subcellular localization of AvrXv4 and XopD transiently expressed in planta. Nicotiana benthamiana leaves were inoculated with a suspension $\left(6 \times 10^{8}\right.$ cells $\left./ \mathrm{ml}\right)$ of Agrobacterium tumefaciens expressing A, enhanced yellow fluorescent protein (EYFP)-AvrXv4, B, EYFP, and C, EYFP-XopD. Epidermal cells in infected leaves were visualized live 24 to $48 \mathrm{~h}$ post inoculation by epifluorescence light microscopy at $\times 10$ (left column) and $\times 40$ (right column). Scale bar equals $10 \mu \mathrm{m}$.
SUMO protein conjugates exists in planta and some of these are SUMO-isoform specific (Hotson et al. 2003; Kurepa et al. 2003; Lois et al. 2003; Murtas et al. 2003). Moreover, the array of SUMOylated proteins in planta significantly increases in response to plant stress (e.g., heat shock, $\mathrm{H}_{2} \mathrm{O}_{2}$, and ethanol) and SUMO modification is readily reversible (Kurepa et al. 2003). SUMO and SUMO modification also have been shown to play an important role in abscisic acid signaling and the regulation of flowering time in A. thaliana (Lois et al. 2003; Murtas et al. 2003). These data indicate that the SUMO pathway may play a regulatory role in many plant responses involving stress, hormones, and development. Currently, nothing is known about the direct effect of pathogen stress on the SUMO pathway in plants or animals. However, SUMO has been shown to interact with fungal elicitors that induce plant defense responses (Hanania et al. 1999), supporting our hypothesis that the SUMO conjugation system may be a key target for some plant pathogens. Furthermore, the large number of SUMO proteases present in A. thaliana (Kurepa et al. 2003) argues that deSUMOylation may be a critical step in SUMO function and regulation in plants.

It is not yet known how plants specifically recognize $X$. campestris pv. vesicatoria YopJ-like effectors during infection; however, resistance to AvrXv4 and AvrBsT has been identified. The wild tomato relative $L$. pennellii is resistant to strains of $X$. campestris pv. vesicatoria expressing AvrXv4 (AstuaMonge et al. 2000). Genetic segregation of AvrXv4-dependent disease resistance revealed that a single dominant gene controls the inheritance of this trait. In addition, resistance to $X$. campestris pv. campestris strains expressing AvrBsT has been identified in A. thaliana (M. B. Mudgett, unpublished). AvrBsT-dependent resistance is conferred by a single recessive gene. We await the cloning of these resistance genes to determine the nature and diversity of disease resistance proteins or signaling components that protect different plant hosts from bacterial SUMO proteases.

In contrast, more is known about how plants recognize $R$. solanacearum YopJ-like effectors. Recently, Deslandes and associates (2003) showed that the $R$. solanacearum YopJ-like effector, PopP2, physically interacts with the RRS1 disease resistance protein from $A$. thaliana. RRS1 is an atypical recessive plant-resistance protein whose structure contains the conserved TIR-NBS-LRR domains found in several dominant resistance proteins and a WRKY domain characteristic of plant transcription factors. Interestingly, when the bacterial effector PopP2 is present in the plant cell, RRS1 moves to the nucleus and colocalizes with PopP2. In the absence of PopP2, RRS1

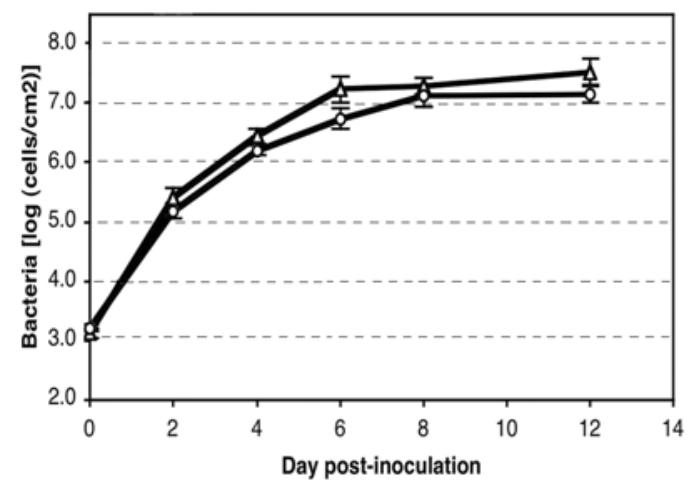

Fig. 7. Growth of AvrXv4 wild-type and mutant Xanthomonas campestris pv. vesicatoria strains in tomato. Plants were hand inoculated with a suspension $\left(1 \times 10^{5}\right.$ cells $\left./ \mathrm{ml}\right)$ of wild-type $X$. campestris $\mathrm{pv}$. vesicatoria 91-118 (open triangle) and mutant $X$. campestris pv. vesicatoria 91-118 avrXv4-(open circle) cells. Data points represent the mean $\log _{10}$ bacterial cells $/ \mathrm{cm}^{2}$ of leaf tissue \pm sample standard deviation. 
remains in the plant cytoplasm (Deslandes et al. 2003). Curiously, both the susceptible and resistant alleles of RRS1 were able to interact and colocalize with PopP2. This suggests that the susceptible RRS1 protein may compete with the resistant RRS1 protein for binding to PopP2. It remains to be determined where RRS1 proteins interact with PopP2 in the plant cell and how such interactions control nuclear trafficking and the activation of plant disease resistance signaling. The localization of PopP2 (Deslandes et al. 2003) and XopD (Hotson et al. 2003) to the plant nucleus and AvrXv4 to the plant cytoplasm suggests that resistance proteins may have evolved to recognize bacterial SUMO proteases in distinct cellular compartments. Determining whether PopP2 also encodes a SUMO protease and if proteolysis is linked to plant defense may shed light on the molecular basis of PopP2 resistance, as well as XopD and YopJ-like resistance, in plants.

In conclusion, we are only just beginning to understand how $X$. campestris pv. vesicatoria use type III effector proteins dur- ing plant infection. The discovery that AvrXv4 and XopD disrupt SUMOylation in plants reveals a novel mechanism used by bacterial pathogens to modulate eukaryotic signal transduction pathways during infection. The abundance of YopJ-like and XopD effectors in X. campestris pv. vesicatoria suggests that these proteases play an important, possibly redundant, role in bacteria-plant interactions. Progress in identifying specific SUMO-protein substrates in plant cells will be essential to fully understand how and why pathogens like $X$. campestris pv. vesicatoria use SUMO protease effectors to manipulate plant signaling pathways that are regulated by SUMO.

\section{MATERIALS AND METHODS}

Bacterial strains, growth, and matings.

Bacterial strains used in this study are described in Table 2. E. coli and Agrobacterium tumefaciens strains were grown in Luria-Bertani medium (Sambrook et al. 1989) at 37 and $28^{\circ} \mathrm{C}$,

Table 2. Bacterial strains and plasmids used in this study

\begin{tabular}{|c|c|c|}
\hline Strain or plasmid & Relevant characteristics $^{\mathbf{a}}$ & References \\
\hline \multicolumn{3}{|l|}{ Bacteria } \\
\hline \multicolumn{3}{|l|}{ Xanthomonas campestris pv. vesicatoria } \\
\hline \multicolumn{3}{|l|}{ Wild-type strain } \\
\hline $85-10$ & $\operatorname{Rif}^{\mathrm{r}}$ & Minsavage et al. 1990 \\
\hline $91-118$ & 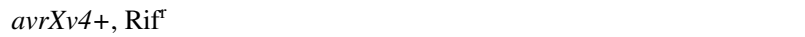 & Astua-Monge et al. 2000 \\
\hline \multicolumn{3}{|l|}{ Mutants } \\
\hline $85-10 \operatorname{hrp}^{*}\left(85^{*}\right)$ & Rif $^{\mathrm{T}}$, HrpG constitutive mutant & Rossier et al. 1999 \\
\hline 85-10 hrpG*, $\Delta h r c V$ & $\mathrm{Rif}^{\mathrm{r}}, h r c V$ nonpolar mutant & Wengelnik et al. 1999 \\
\hline 85-10 hrpG*, $\Delta h r p F$ & Rif $^{\mathrm{r}}, h r p F$ nonpolar mutant & Casper-Lindley et. al. 2002 \\
\hline $91-118$ avrXv4- & 91-118 marker exchange, avrXv4 mutant, $\mathrm{Rif}^{\mathrm{r}}, \mathrm{Km}^{\mathrm{r}}$ & This study \\
\hline \multicolumn{3}{|l|}{$X$. campestris pv. campestris } \\
\hline 8004 & $\operatorname{Rif}^{\mathrm{r}}$ & B. Staskawicz \\
\hline \multicolumn{3}{|l|}{ Agrobacterium tumefaciens } \\
\hline $\mathrm{C} 58 \mathrm{C} 1, \mathrm{pCH} 32$ & $\operatorname{Rif}^{\mathrm{r}}, \mathrm{Tc}^{\mathrm{r}}$ & Tai et al., 1999 \\
\hline C58C1, pCH32, pATC940(HA-SUMO) & $\operatorname{Rif}^{\mathrm{r}}, \mathrm{Km}^{\mathrm{r}}$ & Hotson et al. 2003 \\
\hline $\mathrm{C} 58 \mathrm{C} 1, \mathrm{pCH} 32, \mathrm{pMDD} 1\left(\mathrm{XopD}-\mathrm{HA}_{1-545}\right)$ & $\operatorname{Rif}^{\mathrm{r}}, \mathrm{Km}^{\mathrm{r}}$ & Hotson et al. 2003 \\
\hline C58C1, pCH32, pMDD1(XopD-HA ${ }_{1-545}$ C470A) & $\mathrm{Rif}^{\mathrm{r}}, \mathrm{Km}^{\mathrm{r}}$ & Hotson et al. 2003 \\
\hline \multicolumn{3}{|c|}{ Escherichia coli } \\
\hline $\mathrm{DH} 5 \alpha$ & $\mathrm{Nal}^{\mathrm{r}}$ & Invitrogen \\
\hline C2110, pXcvT3-60::33 & $\mathrm{Nal}^{\mathrm{r}}, \mathrm{Tc}^{\mathrm{r}}, \mathrm{Km}^{\mathrm{r}}$ & Astua-Monge et al. 2000 \\
\hline \multicolumn{3}{|l|}{ Plasmids } \\
\hline pVSP61 & $\mathrm{Km}^{\mathrm{r}}$ & Mudgett et al. 2000 \\
\hline pDD62 & pVSP61 derivative, $\mathrm{Km}^{\mathrm{r}}$ & Mudgett et al. 2000 \\
\hline $\mathrm{pVSP} 61\left(a v r X v 4_{1-100}: \because c y a\right)$ & 1.7-kb XhoI-EcoRI fragment from pMS107(avrXv4 $\left.4_{1-100}:: c y a\right)$ & This study \\
\hline pVSP61 (avrXv4::cya) & 2.5-kb XhoI-EcoRI fragment from pMS107(avrXv4::cya) & This study \\
\hline $\operatorname{pMS} 107\left(a v r X v 4_{1-100}: c y a\right)$ & $0.5-\mathrm{kb} B g l \mathrm{II} a v r X v 4_{1-100}$ fragment (197 bp of $a v r X v 4$ promoter) & This study \\
\hline $\operatorname{pMS} 107(a v r X v 4:: c y a)$ & $1.3-\mathrm{kb} B g l \mathrm{II} a v r X v 4$ fragment ( $197 \mathrm{bp}$ of $a v r X v 4$ promoter) & This study \\
\hline $\mathrm{pDD} 62(a v r X v 4)$ & $1.3-\mathrm{kb} a v r X v 4$ fragment (197 bp of $a v r X v 4$ promoter), $1-359$ aa & This study \\
\hline pDD62(avrXv4::HA) & pDD62 $(a v r X v 4)$ with HA epitope tag & This study \\
\hline pDD62(avrXv4::HA H155A) & pDD62(avrXv4::HA) with alanine substitution at His 155 & This study \\
\hline pDD62(avrXv4::HA E175A) & pDD62(avrXv4::HA) with alanine substitution at Glu 175 & This study \\
\hline pDD62(avrXv4::HA C219A) & pDD62(avrXv4::HA) with alanine substitution at Cys 219 & This study \\
\hline pDD62(avrXv4::HA 20-359) & pDD62( $a v r X v 4: \because H A)$ with $2-19$ aa deleted & This study \\
\hline pDD62(avrXv4::HA 40-359) & pDD62 $(a v r X v 4 \because \because H A)$ with 2-39 aa deleted & This study \\
\hline pDD62(avrXv4::HA 60-359) & pDD62(avrXv4::HA) with 2-59 aa deleted & This study \\
\hline pDD62(avrXv4::HA 80-359) & pDD62 $(a v r X v 4: \because H A)$ with $2-79$ aa deleted & This study \\
\hline pDD62(avrXv4::HA 94-359) & pDD62( $\operatorname{cvr} X v 4: \because H A)$ with $2-89$ aa deleted & This study \\
\hline pMDD1 & RK2 replicon, replicates in $A$. tumefaciens, CaMV $35 \mathrm{~S}$ promoter, $\mathrm{Km}^{\mathrm{r}}$ & Mudgett et al. 2000 \\
\hline $\mathrm{pMDD} 1(\operatorname{avr} X v 4)$ & 1.1-kb XhoI avrXv4 fragment, promoterless, $1-359$ aa & This study \\
\hline $\operatorname{pMDD} 1(a v r X v 4: \because H A)$ & pMDD1 $(a v r X v 4)$ with HA epitope tag & This study \\
\hline pMDD1(avrXv4::HA H155A) & pMDD1 $(a v r X v 4:: H A)$ with alanine substitution at His 155 & This study \\
\hline pMDD1( $a v r X v 4:: H A$ E175A) & pMDD1 $(a v r X v 4:: H A)$ with alanine substitution at Glu 175 & This study \\
\hline pMDD1(avrXv4::HA C219A) & pMDD1 $(a v r X v 4:: H A)$ with alanine substitution at Cys 219 & This study \\
\hline pMDD1(avrXv4::HA 20-359) & pMDD1 $(a v r X v 4: \because H A)$ with $2-19$ aa deleted & This study \\
\hline pMDD1(avrXv4::HA 40-359) & pMDD1 $(a v r X v 4: \because H A)$ with $2-39$ aa deleted & This study \\
\hline pMDD1(avrXv4::HA 60-359) & pMDD1 $(a v r X v 4: \because H A)$ with $2-59$ aa deleted & This study \\
\hline pMDD1( $a v r X v 4: \because H A 80-359)$ & pMDD1 $(a v r X v 4: \because H A)$ with $2-79$ aa deleted & This study \\
\hline pMDD1( $a v r X v 4: \because H A 94-359)$ & pMDD1 $(a v r X v 4: \because H A)$ with $2-89$ aa deleted & This study \\
\hline pEZRK-LCY & yfp, $\mathrm{Km}^{\mathrm{r}}$ & D. Ehrhardt \\
\hline pEZRK-LCY $(y f p:: a v r X v 4)$ & 1.1-kb EcoRI $a v r X v 4$ fragment fused to $3^{\prime}$ end of $y f p$ & This study \\
\hline pXcvT3-60::33 & avrXv4::Tn3-uidA derivatives, $a v r X v 4$ mutant, $\mathrm{Tc}^{\mathrm{r}}, \mathrm{Km}^{\mathrm{r}}$ & Astua-Monge et al. 2000 \\
\hline
\end{tabular}

\footnotetext{
${ }^{\mathrm{a}}$ Abbreviations: $\mathrm{Rif}=$ rifampicin, $\mathrm{Tc}=$ tetracycline, $\mathrm{Km}=$ kanamycin, $\mathrm{Nal}=$ nalidixic acid, and aa $=$ amino acids.
} 
respectively. $X$. campestris pv. vesicatoria and $X$. campestris $\mathrm{pv}$. campestris strains were grown in NYGB liquid media or on NYGA agar plates (Turner et al. 1984) at $28^{\circ} \mathrm{C}$. Vectors were mobilized from $E$. coli into $X$. campestris pv. vesicatoria, $X$. campestris pv. campestris, and Agrobacterium tumefaciens by triparental matings using standard methods. Antibiotics were used for plate selection at the following concentrations: kanamycin $(\mathrm{Km})$ at $50 \mu \mathrm{g} / \mathrm{ml}$, rifampicin (Rif) at $100 \mu \mathrm{g} / \mathrm{ml}$, and tetracycline (Tc) at $5 \mu \mathrm{g} / \mathrm{ml}$ with Agrobacterium tumefaciens or 10 $\mu \mathrm{g} / \mathrm{ml}$ with $X$. campestris pv. vesicatoria. The concentration of antibiotics used in liquid cultures was decreased by half.

\section{Gene manipulation and plasmid construction.}

Polymerase chain reaction (PCR) was used to construct gene fusions, deletions, and mutations. PCR-generated DNA fragments were cloned into pCR2.1 or pCRII TOPO vectors (Invitrogen, Carlsbad, CA, U.S.A.). Primers and conditions used for PCR are available on request. The sequence of DNA constructs was verified by cycle sequencing. For expression in $X$. campestris pv. vesicatoria or $X$. campestris pv. campestris, constructs were cloned into pVSP61 or a derivative, pDD62. The expression of each gene in $X$. campestris pv. campestris and $X$. campestris pv. vesicatoria was under the control of the native AvrXv4 promoter. For transient expression using Agrobacterium tumefaciens, constructs were made in pMDD1. The expression of each gene in planta was under the control of the constitutive CaMV 35S promoter. All plasmids constructed for this study are listed in Table 2.

\section{Secretion assay.}

$X$. campestris pv. vesicatoria strains $85^{*}, 85^{*} \Delta h r c V$, and $85^{*} \Delta h r p F$ were grown for $48 \mathrm{~h}$ at $28^{\circ} \mathrm{C}$ on NYGA selection plates. Fresh cells were resuspended in NYGB and pelleted at $2,600 \times g$ for $10 \mathrm{~min}$ at room temperature. Cells were washed with $1 \mathrm{mM} \mathrm{MgCl}_{2}$, repelleted, and resuspended in $1 \mathrm{mM}$ $\mathrm{MgCl}_{2}$. Bacteria were diluted to $4 \times 10^{8} \mathrm{CFU}$ in $4 \mathrm{ml}$ of secretion media, pH 5.4 (Rossier et al. 1999), containing 5 rifampicin at $\mu \mathrm{g} / \mathrm{ml}$ and bovine serum albumen at $50 \mu \mathrm{g} / \mathrm{ml}$. Cultures were shaken for $4 \mathrm{~h}$ at $28^{\circ} \mathrm{C}$. To obtain cellular lysate fractions, $125 \mu \mathrm{l}$ of each culture was precipitated with $10 \%$ trichloroacetic acid (TCA) on ice for $30 \mathrm{~min}$. Culture fluid fractions were obtained by removing cells from the remaining culture by centrifugation and filtering supernatants through a $0.45-\mu \mathrm{m}$ filter (HT Tuffryn; Gelman, Ann Arbor, MI, U.S.A.). Filtrates also were precipitated with $10 \%$ TCA. Protein from both fractions was collected by centrifugation at $20,000 \times g$ for $30 \mathrm{~min}$ at $4^{\circ} \mathrm{C}$. Pellets were washed with $100 \%$ ethanol and resuspended with $40 \mu \mathrm{l}$ of sample buffer (Mudgett and Staskawicz 1999). Cellular lysate fraction $(20 \mu \mathrm{l})$ and $30 \mu \mathrm{l}$ of the culture fluid fraction were analyzed on protein gels by immunoblot analysis.

\section{Cya protein translocation assay.}

To determine Cya enzyme activity in vitro, total protein was isolated from $X$. campestris pv. vesicatoria strains 85-10 $h r p G^{*}$ (Rossier et al. 1999), and X. campestris pv. vesicatoria 85-10 $h_{r p} G^{*} \Delta h r p F$ (Casper-Lindley et al. 2002) carrying pVSP61(avrXv4::cya) and pVSP61 $\left(a v r X v 4_{(1-100)}: \because H A\right)$ and then assayed as previously described (Casper-Lindley et al. 2002). To determine Cya enzyme activity in vivo, $X$. campestris pv. vesicatoria strains were hand infiltrated into susceptible pepper leaves (cv. Early Calwonder; genotype $b s 2, b s 2$ ) through a small wound using a 1-cc syringe. Leaves were inoculated with a suspension of bacteria $\left(5 \times 10^{8}\right.$ cells $\left./ \mathrm{ml}\right)$ in 1 $\mathrm{mM} \mathrm{MgCl} 2$. Four leaf disks $\left(0.7 \mathrm{~cm}^{2}\right.$ each $)$ were collected in a microfuge tube, frozen in liquid nitrogen, and then processed as previously described (Casper-Lindley et al. 2002). cAMP was measured using the cAMP Biotrak Enzymeimmunoassay System (Amersham Biosciences, Piscataway, NJ, U.S.A.). A modification of the Lowry procedure (Bailey 1967) was used to determine the concentration of protein after precipitation with $1 \mathrm{ml}$ of $10 \%$ TCA. Cya enzyme activity is expressed as nmol of cAMP per mg of total protein.

\section{Plant growth and bacterial inoculation.}

Pepper plants (cv. Early Calwonder; genotype $b s 2$, $b s 2$ ) were used for $X$. campestris pv. vesicatoria inoculations for Cya translocation assays. $N$. benthamiana plants were used for $X$. campestris pv. campestris and Agrobacterium tumefaciens inoculations. L. pennellii plants were used for X. campestris pv. vesicatoria AvrXv4 HR analysis and L. esculentum (variety VF36) was used for $X$. campestris pv. vesicatoria growth curves. Plants were grown under greenhouse conditions. Bacteria were hand infiltrated into plant leaves through a small wound by using a 1-cc syringe.

\section{Agrobacterium-mediated transient expression assay.}

Agrobacterium tumefaciens C58C1 pCH32 (Tai et al. 1999) was used for transient expression in planta. Strains were grown overnight at $28^{\circ} \mathrm{C}$ on Luria agar medium containing Rif at $100 \mu \mathrm{g} / \mathrm{ml}$, Tc at $5 \mu \mathrm{g} / \mathrm{ml}$, and $\mathrm{Km}$ at $35 \mu \mathrm{g} / \mathrm{ml}$. Bacteria were collected and incubated in induction media (10 mM MES [morpholineethanesulfonic acid], $\mathrm{pH} 5.6,10 \mathrm{mM} \mathrm{MgCl}_{2}$, and $150 \mu \mathrm{M}$ acetosyringone) (ACROS Organics, Morris Plains, NJ, U.S.A.) for $2 \mathrm{~h}$ before inoculation. For single bacterial inoculations, $N$. benthamiana and pepper leaves were hand inoculated with a suspension of bacteria $\left(6 \times 10^{8}\right.$ cells $\left./ \mathrm{ml}\right)$ induction media. For co-inoculations, strains were mixed equally and injected into the leaf at a final density of $1.2 \times 10^{9}$ cells $/ \mathrm{ml}$. Plants were incubated at room temperature under continuous low light. Samples were collected 24 to $48 \mathrm{~h}$ postinoculation. Protein expression was detected by immunoblot analysis.

\section{Protein gels and immunoblot analysis.}

Proteins were separated by sodium dodecyl sulfate gel electrophoresis analysis and analyzed by immunoblot analysis as previously described (Mudgett et al. 2000). Proteins were visualized by chemiluminescence using monoclonal Cya antiserum (courtesy of N. Giuso, Institut Pasteur, Paris), monoclonal HA antiserum (Covance, Berkeley, CA, U.S.A.), polyclonal NPTII antiserum (obtained from $5^{\prime}$ to $3^{\prime}$ ), monoclonal GFP antiserum (Clontech, Palo Alto, CA, U.S.A.), and peroxidase-conjugated secondary antibodies (Bio-Rad, Hercules, CA, U.S.A.).

\section{Microscopy.}

Agrobacterium tumefaciens-infected $N$. benthamiana leaves were analyzed $48 \mathrm{~h}$ after inoculation. Leaf disks were placed on a slide and visualized using a $10 \times$ and $40 \times$ objective lens on an inverted microscope (TE200; Nikon, Tokyo). Fluorescence microscopy was performed with a trichroic filter set (Chroma 86006) using excitation at $493 \pm 17 \mathrm{~nm}$ with image collection through a band emission filter (530 \pm 40 $\mathrm{nm})$. Images were collected with a cooled CCD camera (model 1300; Princeton Instruments, Adelphia, NJ, U.S.A.) at 12-bit precision (Diagnostic Instruments, Sterling Heights, MI, U.S.A.).

\section{Mutagenesis of $a v r X v 4$}

in $X$. campestris pv. vesicatoria chromosome.

The cosmid clone pXcvT3-60 containing the $a v r X v 4$ gene was mutagenized previously by transposon insertion with Tn3-uidA (Astua-Monge et al. 2000). The transposon avrXv4 
mutant derivative in pXcvT3-60::33 (generous gift from G. Minsavage and J. Jones) exchanged with the wild-type copy of avrXv4 in $X$. campestris pv. vesicatoria strain $91-118$ by triparental mating. Transconjugants were transferred daily for a week on NYGA containing Rif and $\mathrm{Km}$. Bacterial cells that were resistant to Rif and $\mathrm{Km}$ and sensitive to Tc were collected and then screened for their inability to elicit HR in $L$. pennellii and $N$. benthamiana. Strains lacking avrXv4dependent HR activity were analyzed by Southern hybridization to confirm marker exchange and then used for the in planta $X$. campestris pv. vesicatoria growth curve analysis.

\section{In planta $X$. campestris pv. vesicatoria growth curve.}

To determine $X$. campestris pv. vesicatoria growth in L. esculentum VF36 plants, leaves were hand inoculated with bacterial suspensions of $1 \times 10^{5}$ cells $/ \mathrm{ml}$. Bacteria in the leaves were sampled by grinding two leaf disks (no. 3 cork borer) in $1 \mathrm{mM} \mathrm{MgCl} 2$ and plating appropriate dilution on NYGA containing appropriate antibiotics and cyclohexamide $(50 \mu \mathrm{g} / \mathrm{ml})$. Bacterial growth was assayed 0, 2, 4, 8, and 12 days after inoculation. Three replicates were taken for each sampling.

\section{ACKNOWLEDGMENTS}

We thank B. Staskawicz, D. Dahlbeck, D. Ehrhardt, G. Minsavage, and J. Jones for generously providing strains and plasmids.

\section{LITERATURE CITED}

Abramovitch, R. B., Kim, Y. J., Chen, S., Dickman, M. B., and Martin, G. B. 2003. Pseudomonas type III effector AvrPtoB induces plant disease susceptibility by inhibition of host programmed cell death. EMBO (Eur. Mol. Biol. Organ.) J. 22:60-69.

Astua-Monge, G., Minsavage, G. V., Stall, R. E., Vallejos, C. E., Davis, M. J., and Jones, J. B. 2000. Xv4-AvrXv4: A new gene-for-gene interaction identified between Xanthomonas campestris pv. vesicatoria race T3 and the wild tomato relative Lycopersicon pennellii. Mol. Plant Microbe Interact. 13:1346-1355.

Bailey, J. L. (1967) Techniques in Protein Chemistry. Elsevier, New York.

Bonas, U., Schulte, R., Fenselau, S., Minsavage, G. V., Staskawicz, B. J., and Stall, R. E. 1991. Isolation of a gene cluster from Xanthomonas campestris pv. vesicatoria that determines pathogenicity and the hypersensitive response on pepper and tomato. Mol. Plant-Microbe Interact. 4:81-88.

Buttner, D., and Bonas, U. 2002. Getting across-bacterial type III effector proteins on their way to the plant cell. EMBO (Eur. Mol. Biol. Organ.) J. 21:5313-5322.

Buttner, D., Nennstiel, D., Klusener, B., and Bonas, U. 2002. Functional analysis of HrpF, a putative type III translocon protein from Xanthomonas campestris pv. vesicatoria. J. Bacteriol. 184: 2389-2398.

Casper-Lindley, C., Dahlbeck, D., Clark, E. T., and Staskawicz, B. J. 2002. Direct biochemical evidence for type III secretion-dependent translocation of the AvrBs2 effector protein into plant cells. Proc. Natl. Acad. Sci. U.S.A. 99:8336-8341.

Chang, J. H., Rathjen, J. P., Bernal, A. J., Staskawicz, B. J., and Michelmore, R. W. 2000. avrPto enhances growth and necrosis caused by Pseudomonas syringae pv. tomato in tomato lines lacking either Pto or Prf. Mol. Plant-Microbe Interact. 13:568-571.

Ciesiolka, L. D., Hwin, T., Gearlds, J. D., Minsavage, G. V., Saenz, R., Bravo, M., Handley, V., Conover, S. M., Zhang, H., Caporgno, J., Phengrasamy, N. B., Toms, A. O., Stall, R. E., and Whalen, M. C. 1999. Regulation of expression of avirulence gene avrRxv and identification of a family of host interaction factors by sequence analysis of avrBsT. Mol. Plant-Microbe Interact. 12:35-44.

Collmer, A., Lindeberg, M., Petnicki-Ocwieja, T., Schneider, D. J., and Alfano, J. R. 2002. Genomic mining type III secretion system effectors in Pseudomonas syringae yields new picks for all TTSS prospectors. Trends Microbiol. 10:462-469.

Dangl, J. L., and Jones, J. D. 2001. Plant pathogens and integrated defence responses to infection. Nature 411:826-833.

da Silva, A. C., Ferro, J. A., Reinach, F. C., Farah, C. S., Furlan, L. R., Quaggio, R. B., Monteiro-Vitorello, C. B., et al. 2002. Comparison of the genomes of two Xanthomonas pathogens with differing host specificities. Nature 417:459-463.
Deslandes, L., Olivier, J., Peeters, N., Feng, D. X., Khounlotham, M., Boucher, C., Somssich, I., Genin, S., and Marco, Y. 2003. Physical interaction between RRS1-R, a protein conferring resistance to bacterial wilt, and PopP2, a type III effector targeted to the plant nucleus. Proc. Natl. Acad. Sci. U.S.A. 100:8024-8029.

Desterro, J. M., Rodriguez, M. S., and Hay, R. T. 1998. SUMO-1 modification of IkappaBalpha inhibits NF-kappaB activation. Mol. Cell. 2:233-239.

Duan, Y. P., Castaneda, A., Zhao, G., Erdos, G., and Gabriel, D. W. 1999. Expression of a single, host-specific, bacterial pathogenicity gene in plant cells elicits division, enlargement, and cell death. Mol. PlantMicrobe Interact. 12:556-560.

Fenselau, S., Balbo, I., and Bonas, U. 1992. Determinants of pathogenicity in Xanthomonas campestris pv. vesicatoria are related to proteins involved in the secretion in bacterial pathogens of animals. Mol. PlantMicrobe Interact. 5:390-396.

Greenberg, J. T., and Vinatzer, B. A. 2003. Identifying type III effectors of plant pathogens and analyzing their interaction with plant cells. Curr. Opin. Microbiol. 6:20-28.

Hanania, U., Furman-Matarasso, N., Ron, M., and Avni, A. 1999. Isolation of a novel SUMO protein from tomato that suppresses EIX-induced cell death. Plant J. 19:533-541.

Hauck, P., Thilmony, R., and He, S. Y. 2003. A Pseudomonas syringae type III effector suppresses cell wall-based extracellular defense in susceptible Arabidopsis plants. Proc. Natl. Acad. Sci. U.S.A. 100:8577-8582.

Hotson, A., Chosed, R., Shu, H., Orth, K., and Mudgett, M. B. 2003. Xanthomonas type III effector XopD targets SUMO-conjugated proteins in planta. Mol. Microbiol. 50:377-389.

Hueck, C. J. 1998. Type III protein secretion systems in bacterial pathogens of animals and plants. Microbiol. Mol. Biol. Rev. 62:379-433.

Jackson, R. W., Athanassopoulos, E., Tsiamis, G., Mansfield, J. W. Sesma, A., Arnold, D. L., Gibbon, M. J., Murillo, J., Taylor, J. D., and Vivian, A. 1999. Identification of a pathogenicity island, which contains genes for virulence and avirulence, on a large native plasmid in the bean pathogen Pseudomonas syringae pathovar phaseolicola. Proc. Natl. Acad. Sci. U.S.A. 96:10875-10880.

Kurepa, J., Walker, J. M., Smalle, J., Gosink, M. M., Davis, S. J., Durham, T. L., Sung, D. Y., and Vierstra, R. D. 2003. The small ubiquitin-like modifier (SUMO) protein modification system in Arabidopsis. Accumulation of SUMO1 and -2 conjugates is increased by stress. J. Biol. Chem. 278:6862-6872.

Li, S. J., and Hochstrasser, M. 1999. A new protease required for cellcycle progression in yeast. Nature 398:246-251.

Li, S. J., and Hochstrasser, M. 2003. The Ulp1 SUMO isopeptidase: Distinct domains required for viability, nuclear envelope localization, and substrate specificity. J. Cell Biol. 160:1069-1081.

Lois, L. M., Lima, C. D., and Chua, N. H. 2003. Small ubiquitin-like modifier modulates abscisic acid signaling in Arabidopsis. Plant Cell $15: 1347-1359$.

Melchoir, F. 2000. SUMO-nonclassical ubiquitin. Annu. Rev. Cell Dev. Biol. 16:591-626.

Mudgett, M. B., Chesnokova, O., Dahlbeck, D., Clark, E. T., Rossier, O., Bonas, U., and Staskawicz, B. J. 2000. Molecular signals required for type III secretion and translocation of the Xanthomonas campestris AvrBs2 protein to pepper plants. Proc. Natl. Acad. Sci. U.S.A. 97:13324-13329.

Mudgett, M. B., and Staskawicz, B. J. 1999. Characterization of the Pseudomonas syringae pv. tomato AvrRpt2 protein: demonstration of secretion and processing during bacterial pathogenesis. Mol. Microbiol 32:927-941.

Murtas, G., Reeves, P. H., Fu, Y. F., Bancroft, I., Dean, C., and Coupland, G. 2003. A nuclear protease required for flowering-time regulation in Arabidopsis reduces the abundance of SMALL UBIQUITINRELATED MODIFIER conjugates. Plant Cell 15:2308-2319.

Noel, L., Thieme, F., Nennstiel, D., and Bonas, U. 2001. cDNA-AFLP analysis unravels a genome-wide hrpG-regulon in the plant pathogen Xanthomonas campestris pv. vesicatoria. Mol. Microbiol. 41:12711281.

Noel, L., Thieme, F., Nennstiel, D., and Bonas, U. 2002. Two novel type IIIsecreted proteins of Xanthomonas campestris pv. vesicatoria are encoded within the hrp pathogenicity island. J. Bacteriol. 184:1340-1348.

Orth, K. 2002. Function of the Yersinia effector YopJ. Curr. Opin. Microbiol. 5:38-43.

Orth, K., Xu, Z. H., Mudgett, M. B., Bao, Z. Q., Palmer, L. E., Bliska, J. B., Mangel, W. F., Staskawicz, B., and Dixon, J. E. 2000. Disruption of signaling by Yersinia effector YopJ, a ubiquitin-like protein protease. Science 290:1594-1597.

Reuber, T. L., and Ausubel, F. M. 1996. Isolation of Arabidopsis genes that differentiate between resistance responses mediated by the RPS2 and RPM1 disease resistance genes. Plant Cell 8:241-249. 
Ritter, C., and Dangl, J. L. 1995. The avrRPm1 gene of Pseudomonas syringae pv. maculicola is required for virulence on Arabidopsis. Mol. Plant-Microbe Interact. 8:444-453.

Rossier, O., Wengelnik, K., Hahn, K., and Bonas, U. 1999. The Xanthomonas Hrp type III system secretes proteins from plant and mammalian bacterial pathogens. Proc. Natl. Acad. Sci. U.S.A. 96:9368-9373.

Sambrook, J., Fritsch, E. F., and Maniatis, T. 1989. Molecular Cloning: A Laboratory Manual. Cold Spring Harbor Laboratory Press, Cold Spring Harbor, NY, U.S.A.

Scofield, S. R., Tobias, C. M., Rathjen, J. P., Chang, J. H., Lavelle, D. T., Michelmore, R. W., and Staskawicz, B. J. 1996. Molecular basis of gene-for-gene specificity in bacterial speck disease of tomato. Science 274:2063-2065.

Sory, M. P., and Cornelis, G. R. 1994. Translocation of a hybrid YopEadenylate cyclase from Yersinia enterocolitica into HeLa cells. Mol. Microbiol. 14:583-594.

Tai, T. H., Dahlbeck, D., Clark, E. T., Gajiwala, P., Pasion, R., Whalen, M. C., Stall, R. E., and Staskawicz, B. J. 1999. Expression of the Bs2 pepper gene confers resistance to bacterial spot disease in tomato. Proc. Natl. Acad. Sci. U.S.A. 96:14153-14158.

Tang, X., Frederick, R. D., Zhou, J., Halterman, D. A., Jia, Y., and Martin, G. B. 1996. Initiation of plant disease resistance by physical interaction of AvrPto and Pto kinase. Science 274:2060-2063.

Tsiamis, G., Mansfield, J. W., Hockenhull, R., Jackson, R. W., Sesma, A.,
Athanassopoulos, E., Bennett, M. A., Stevens, C. Vivian, A., Taylor, J. D., and Murillo, J. 2000. Cultivar-specific avirulence and virulence functions assigned to avrPphF in Pseudomonas syringae pv. phaseolicola, the cause of bean halo-blight disease. EMBO (Eur. Mol. Biol. Organ.) J. 19:3204-3214.

Turner, P., Barber, C., and Daniels, M. 1984. Behaviour of the transposons Tn5 and Tn7 in Xanthomonas campestris pv. campestris. Mol. Gen. Genet. 195:101-107.

Wengelnik, K., Rossier, O., and Bonas, U. 1999. Mutations in the regulatory gene hrpG of Xanthomonas campestris pv. vesicatoria result in constitutive expression of all hrp genes. J. Bacteriol. 181:6828-6831.

Whalen, M. C., Stall, R. E., and Staskawicz, B. J. 1988. Characterization of a gene from a tomato pathogen determining hypersensitive resistance in non-host species and genetic analysis of this resistance in bean. Proc. Natl. Acad. Sci. U.S.A. 85:6743-6747.

White, F. F., Yang, B., and Johnson, L. B. 2000. Prospects for understanding avirulence gene function. Curr. Opin. Plant Biol. 3:291-298.

\section{AUTHOR-RECOMMENDED INTERNET RESOURCES}

MEROPS protease database: merops.sanger.ac.uk

PSORT program for the prediction of protein localization sites: psort.nibb.ac.jp 